\title{
Experimental Study on Bond Behavior of FRP-Concrete Interface in Hygrothermal Environment
}

\author{
X. H. Zheng, ${ }^{1}$ P. Y. Huang, ${ }^{1}$ X. Y. Guo, ${ }^{1}$ and J. L. Huang ${ }^{2}$ \\ ${ }^{1}$ School of Civil Engineering and Transportation, South China University of Technology, Guangzhou 510640, China \\ ${ }^{2}$ College of Water Conservancy and Civil Engineering, South China Agriculture University, Guangzhou 510642, China \\ Correspondence should be addressed to P. Y. Huang; pyhuang@scut.edu.cn
}

Received 23 September 2016; Accepted 13 November 2016

Academic Editor: Baolin Wan

Copyright (c) 2016 X. H. Zheng et al. This is an open access article distributed under the Creative Commons Attribution License, which permits unrestricted use, distribution, and reproduction in any medium, provided the original work is properly cited.

\begin{abstract}
As the technique of fiber-reinforced polymer (FRP) composite material strengthened reinforced concrete structures is widely used in the field of civil engineering, durability of the strengthened structures has attracted more attention in recent years. Hygrothermal environment has an adverse effect on the bond behavior of the interface between FRP and concrete. This paper focuses on the bond durability of carbon fiber laminate- (CFL-) concrete interface in hygrothermal condition which simulates the climate characteristic in South China. Twenty $100 \mathrm{~mm} \times 100 \mathrm{~mm} \times 720 \mathrm{~mm}$ specimens were divided into 6 groups based on different temperature and humidity. After pretreatment in hygrothermal environment, the specimens were tested using double shear method. Strain gauges bonded along the CFL surface and linear variation displacement transducers (LVDTs) were used to measure longitudinal strains and slip of the interface. Failure mode, ultimate capacity, load-deflection relationship, and relative slip were analyzed. The bond behavior of FRP-concrete interface under hygrothermal environment was studied. Results show that the ultimate bearing capacity of the interface reduced after exposure to hygrothermal environments. The decreasing ranges were up to $27.9 \%$ after exposure at high temperature and humidity $\left(60^{\circ} \mathrm{C}, 95 \% \mathrm{RH}\right)$. The maximum strains $\left(\varepsilon_{\max }\right)$ of the specimens pretreated decreased obviously which indicated decay of the bond behavior after exposure to the hygrothermal environment.
\end{abstract}

\section{Introduction}

External bonding of fiber-reinforced polymer (EB-FRP) composite material is a popular technique for strengthening concrete structures [1-3]. In this method, the adhesively bonded joint plays a crucial role which provides effective stress transferring from concrete to FRP to secure the integrity and durability of the strengthened structures [4-6]. In recent years, the durability of FRP-concrete bond interface attracted more attention, and a number of experimental programs have been conducted to examine the behavior of FRP-concrete interface exposed to aggressive conditions [711]. Temperature and moisture, the two dominant conditions, have significant impacts on a variety of mechanical and durability issues. Exposure to high temperature and humidity can result in adhesive bond degradation [12-21] which causes a rapid decrease in efficiency of the entire strengthened system.
Wan et al. [12] studied the moisture effects on the durability of FRP/concrete bond. After 8 weeks of immersion in the water, the energy release rate of bonded interface was found soundly reduced by $85 \%$. Benzarti et al. [13] designed 4 different composite systems to study the CFRP-to-concrete bond durability under constant hydrothermal ageing conditions $\left(40^{\circ} \mathrm{C}\right.$ and $95 \%$ relative humidity). The research included two parts of experiments by using pull-off tests and single shear test. The periods of exposure were 20 and 13 months, respectively. It was found that hydrothermal ageing caused a significant reduction in the capacity strength of the bonded interfaces for specimens strengthened with CFS and CFRP compared to the unstrengthened concrete slabs. Moreover, the failure mode changed from a substrate failure to a compound or interfacial failure. The chemical compositions reports explained that moisture diffusion from the superficial layer of concrete towards the adhesive joint is possibly the key reason causing the degradation process during hydrothermal 
ageing. As for the two methods, the shear test was more sensitive than the pull-off test and should be used to evaluate the adhesive bond strength. Gamage et al. [14] studied the bond characteristics of CFRP plated concrete members under elevated temperatures through experimental and numerical analysis. Eleven single shear specimens made of noninsulated CFRP-strengthened concrete blocks were conducted to verify the temperature distributions. Two insulated single shear specimens were tested to determine the effects of insulation on the heat transfer behavior of the concrete bonded with CFRP. On the other hand, finite element analysis program was used to analyze heat transfer. Both experimental and finite element results show that epoxy adhesive being used in the construction industry is very sensitive to temperature variations. The epoxy working temperature should not exceed $70^{\circ} \mathrm{C}$ in order to maintain the integrity between the CFRP and concrete. Silva and Biscaia [15] investigated FRP-concrete bond degradation considering salt fog cycles, temperature, moisture, and immersion in salt water through bending tests. The concrete specimens were externally bonded with GFRP or CFRP. The results showed that failure surfaces differed under different ageing environmental conditions. Temperature cycles $\left(-10^{\circ} \mathrm{C} ; 10^{\circ} \mathrm{C}\right)$ and moisture cycles were found with failure in the concrete substrate, while salt fog cycles failure happened at the interface concrete-adhesive. The temperature cycles caused significant loss of capacity of beams. As for beams bonded with GFRP and CFRP, the corresponding maximum loss of load capacity is $31 \%$ and $20 \%$. Immersion in salt water and salt fog caused considerable degradation of bond between the GFRP strips and concrete. In the literature of Lai et al. [16], a method combining the use of destructive (pull-out) and nondestructive (pulsed IRT) tests was introduced to study the full field debonding process of CFRP-strengthened concrete beam specimens exposed to $45^{\circ} \mathrm{C}$ with different humidity (RH $45 \%, 90 \%$, and water bath) conditions. The exposure durations were 3, 5, 7, and 9 months. Four unexposed control specimens (room temperature at about $23^{\circ} \mathrm{C}$ and $65 \% \mathrm{RH}$ ) and 48 exposed specimens were tested using modified pull-out test. The bonding between the CFRP strips and concrete was found weakened significantly after the specimens were exposed to humid conditions $(\mathrm{RH}>$ 90\%) for several months. Blackburn et al. [17] investigated the effects of hygrothermal environmental conditions on the curing kinetics of epoxy used in FRP composites. Results showed that all clear epoxies experienced a significant decrease in $T_{g}$, ranging from approximately 9 to $25^{\circ} \mathrm{C}$, from their theoretical values due to the exposure to hygrothermal conditions which caused the degradation of the bond interface. Shrestha et al. [18] studied the durability of the FRP-concrete bond and its constituent properties under moisture conditions for duration up to 24 months. The results show that the bond strength decreased up to $32 \%$, and the failure mode changed from concrete cohesion to primer-concrete mixed failure for normal-strength concrete and from mixed failure to complete adhesion failure in case of high-strength concrete. The author explained that shifts in failure patterns were mainly due to destruction of the adhesion bond caused by water molecules at the interface. Mikami et al. [19] examined the effects of hot temperature $\left(100\right.$ and $\left.180^{\circ} \mathrm{C}\right)$ on the deterioration of bond strength and the changes in failure modes. The combination of high temperature and low humidity (at $180^{\circ} \mathrm{C}$ and $0 \%$ humidity) was the most detrimental to bond strength, and the adhesive strength was reduced to $0.5 \mathrm{MPa}$ which was $6.0 \mathrm{MPa}$ at the room environment. Kabir et al. [20] investigated the time dependent behavior of CFRP-concrete bond subjected to temperature cycles, wet-dry cycles, and outdoor environment separately by using single shear tests. The maximum reduction of pull-out strength of CFRP-concrete bond was $15.2 \%$ compared to that for the corresponding unexposed specimens due to degraded epoxy properties. Failure modes changed from thick concrete to very thin concrete layer attached to the FRP except the specimens subjected to temperature cycles. Effective bond length increased due to exposed condition.

In general, humidity and water exposure will cause significant reduction in bond stress of the FRP-concrete interface. However, the research above mostly focused on the bond strength and global durability of the FRP-strengthened concrete specimens. These tests serve to provide strength data in the final state, but limited data are available to explain the load history and the actual failure mechanism before failure. Also the hygrothermal environmental effects on the bond during loading progress were seldom reported. In addition, the studies focusing on the durability of the system in tropical climate are very limited. Information on the effect of aggressive environments on bond durability is still lacking which links to the service life of strengthened structures. Therefore, the long-term performance of FRPconcrete interface needs further research and more data.

This paper reports the study of FRP-strengthened concrete specimens subjected to accelerated hygrothermal (coupled temperature and moisture) attack. Double shear tests were used to test the bond degradation in the specimens. The objectives of this study are twofold: (i) experimentally studying the effects of high temperature and humidity on EB-FRP specimens, mainly on bond between the composite and concrete, and (ii) explaining the hygrothermal environmental effects on bond interface behavior during the loading progress.

\section{Experimental Program}

2.1. Specimens. Twenty specimens were tested by using double shear method in this research. Each specimen consisted of two concrete prisms, with dimensions $100 \mathrm{~mm} \times 100 \mathrm{~mm}$ $\times 250 \mathrm{~mm}$, as shown in Figure 1 . A $\phi 20 \mathrm{~mm}$ ribbed steel bar was inserted at the center location of every prism before cast, by which the tensile force was applied with an electronic machine. To avoid loading eccentrically, a set of steel mold was designed as shown in Figure 2(a). A pair of concrete blocks were casted together in the mold and marked. The three holes where the steel bar passed through were center aligned. The two steel bars were separate at the middle of the mold. All concrete blocks were cast in laboratory conditions and cured in a water bath for 28 days at standard conditions 


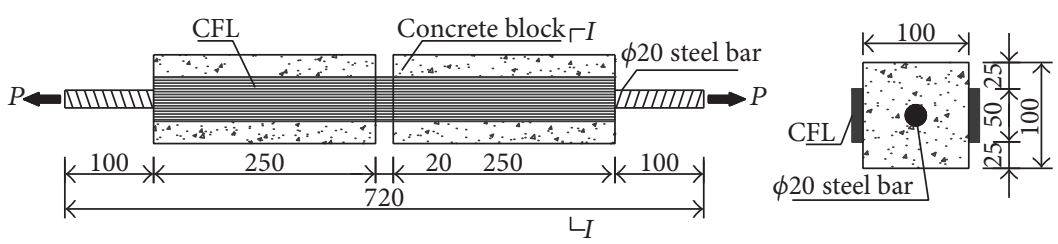

FIgURE 1: Schematic diagram of a double shear specimen (unit: $\mathrm{mm}$ ).

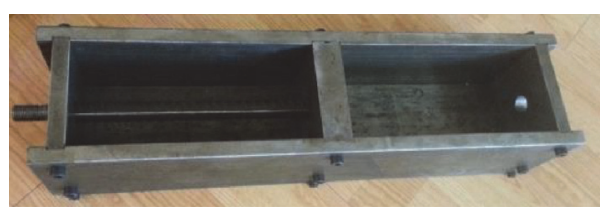

(a) Steel mold for the concrete blocks

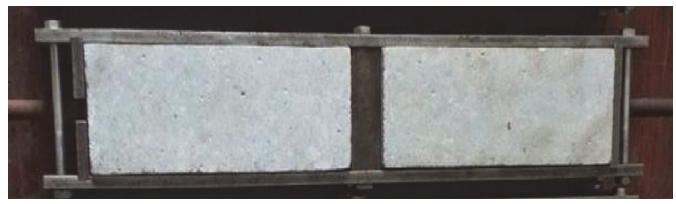

(b) Special fixtures when bonding CFL

FIGURE 2: Molds and fixtures used to make the specimens.

[21]. Then they were removed from the water bath and dried for a week in laboratory.

One pair of concrete blocks were bonded together by FRP to make a specimen. The two concrete prisms were connected only through two carbon fiber laminates (CFL [22]), externally bonded to two opposite sides of the concrete prisms by a wet layup process. Between the two concrete blocks there was a space of $20 \mathrm{~mm}$ (Figure 1). In order to ensure the alignment, special fixture as shown in Figure 2(b) was used when bonding FRP. The bonding process mainly included 3 steps. First, the concrete surface was ground with a stone wheel in order to remove the weak layer of mortar, just until the aggregate was visible. Then the dust on the surface was properly cleaned with air jet. Finally, carbon fiber laminates (CFL [22]) with a width of $50 \mathrm{~mm}$ and a thickness of $0.23 \mathrm{~mm}$ were bonded to the two opposite surfaces of the concrete blocks, respectively, using epoxy resin by wet layup method.

2.2. Material Properties. In this study, the mix proportions of the main ingredients in the concrete by weight were cement (1.0) : water (0.5) : sand (2.06) : gravel (3.66). Chinese standard Portland cement (P.O42.5R) was adopted; river sand with fineness modulus of 2.74 and granite aggregate with diameter of $5-20 \mathrm{~mm}$ were used in the experiment. The mean 28-day cubic $(150 \mathrm{~mm} \times 150 \mathrm{~mm} \times 150 \mathrm{~mm})$ compressive strength of the concrete was $35.4 \mathrm{MPa}$ according to the standard for test method of mechanical properties on ordinary concrete (GB/T 50081-2002 [23]).

The carbon fiber laminates (CFL [22]) used in this test were one kind of FRP invented by our research group, and presaturated laminates were fabricated using T700-12k carbon fibers. The tensile strength, tensile modulus, and elongation of the carbon fibers reported by the manufacturer were $5040 \mathrm{MPa}, 232 \mathrm{GPa}$, and $2.1 \%$, respectively. The measured values of the tensile strength, tensile modulus, and Poisson's ration for CFL were $4030 \mathrm{MPa}, 220 \mathrm{GPa}$, and 0.25 , respectively. The adhesive used for bonding CFL to concrete surface was a two-component epoxy adhesive. The manufacturer reported properties of the epoxy resin were the Young modulus of $2.5 \mathrm{GPa}$, the tensile strength of $40 \mathrm{MPa}$, the ultimate strain of $5.0 \%$, and the vitreous transition temperature of $85^{\circ} \mathrm{C}$. The material properties are summarized in Table 1.

2.3. Hygrothermal Environmental Conditions. In this test, the specimens were moved to pretreatment in an environmental chamber in which temperature and relative humidity $(\mathrm{RH})$ conditions can be preset. The characteristic values of temperature and humidity were chosen according to the measured data of a number of bridges in service in the coastal provinces of South China combined with some relevant codes [24]. The curves of monthly temperature and humidity throughout one year are shown in Figure 3. It indicates that the temperature was from $5^{\circ} \mathrm{C}$ to $50^{\circ} \mathrm{C}$ in service and that for humidity is from $70 \% \mathrm{RH}$ to $95 \% \mathrm{RH}$. According to the Chinese guidelines (GB/T1446-2005 [25] and GB/T2573-2008 [26]), the accelerated condition for hygrothermal environment is $60 \pm 2^{\circ} \mathrm{C}, 93 \pm 3 \%$. The prescribed temperature and $\mathrm{RH}$ conditions in this test were chosen as $5^{\circ} \mathrm{C}, 25^{\circ} \mathrm{C}$, and $60^{\circ} \mathrm{C}$ and $60 \% \mathrm{RH}, 75 \% \mathrm{RH}$, and $95 \% \mathrm{RH}$, respectively.

The temperature and humidity conditions for different groups of specimens are listed in Table 2. The specimens were kept in the environmental chamber as shown in Figure 4 for 14 days in accordance with the Chinese guidelines (GB/T1446-2005 [25] and GB/T2573-2008 [26]). After exposure to the simulated environment, the specimens were taken out from the chamber and dried at air environment in laboratory at an average temperature of $25^{\circ} \mathrm{C}$ with $80 \% \mathrm{RH}$ before testing.

2.4. Test Setup. Double shear tests were carried out to study the bond performance of the FRP-concrete bonded interface 
TABLE 1: Summary of material properties.

\begin{tabular}{lcc}
\hline Materials & Index of material properties & Values \\
\hline Concrete & 28-day cubic compressive strength (MPa) & 35.4 \\
\hline & Guaranteed tensile strength (MPa) & 4030 \\
Carbon fiber laminate & Nominal modulus of elasticity $(\mathrm{GPa})$ & 220 \\
& Poisson's ration & 0.25 \\
\hline & Shear strength (MPa) & 14.0 \\
Epoxy adhesive & Vitreous transition temperature $\left({ }^{\circ} \mathrm{C}\right)$ & 85 \\
& Young modulus (GPa) & 2.5 \\
& Tensile strength (MPa) & 40 \\
\hline
\end{tabular}

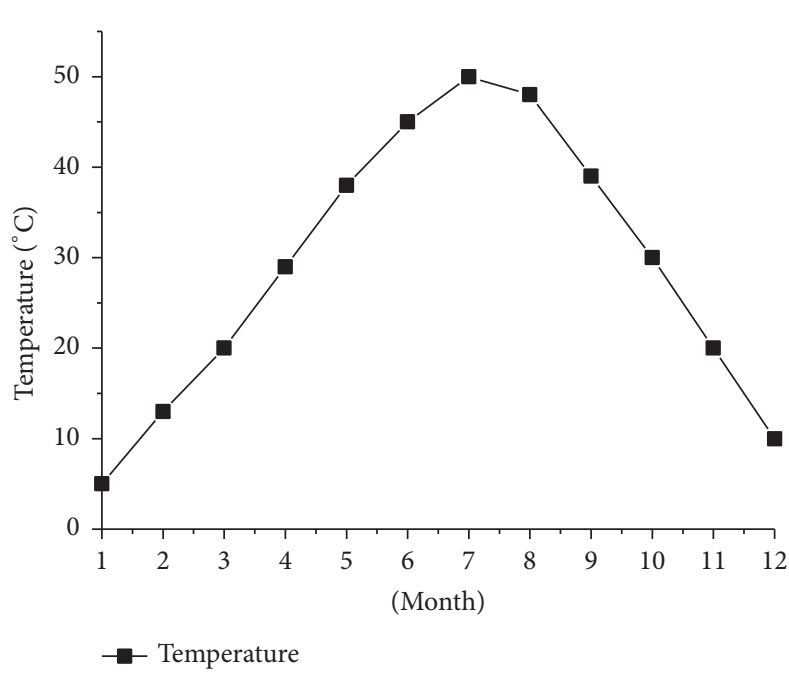

(a)

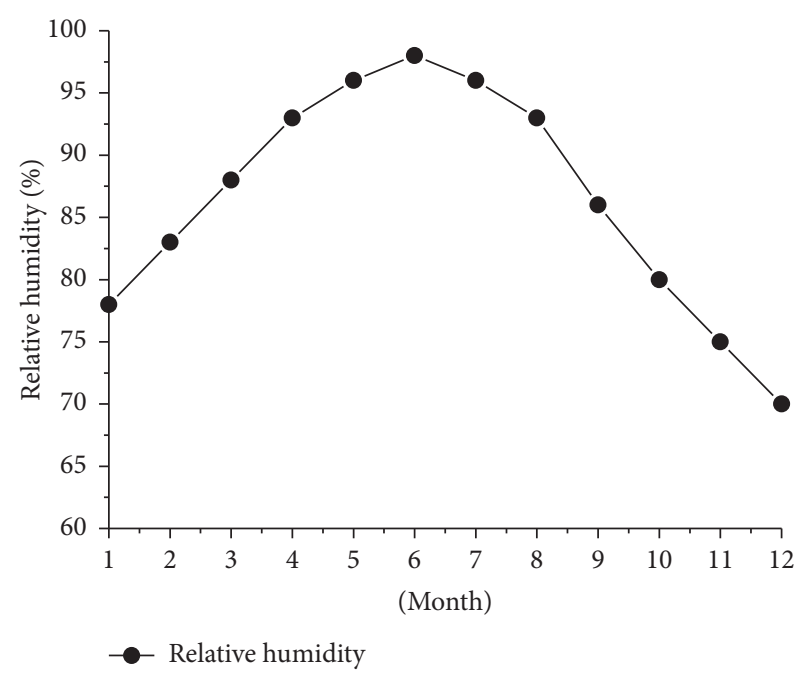

(b)

FIGURE 3: Monthly temperature and humidity curves over one year on the bridges in South China.

using a modified setup. A steel bar was embedded within each concrete block, centered, and aligned with the concrete faces. And the bars extended $100 \mathrm{~mm}$ from the outer ends of each block to be applied tension load $(P$, as shown in Figure 1). The two steel bars were unconnected, which means that the connection of the two concrete blocks was ensured only through the CFL sheet. Special care was taken during the installation of the formwork to position the internal steel reinforcement perfectly aligned. Additional strain gauges were bonded at the same location on opposite face of the specimen to check the coaxial condition before test.

All specimens were tested on an electronic universal testing machine (CMT5105) with $100 \mathrm{kN}$ capacity as shown in Figure 5. Loading was controlled in displacement mode at a rate of $0.005 \mathrm{~mm} / \mathrm{s}$. Strain gauges were externally bonded on the CFL to measure the strains in CFL. A total of 13 strain gauges were distributed along the bonded length of CFL with a center-to-center spacing of $20 \mathrm{~mm}$ as shown in Figure 6(a). During the test, strains were automatically recorded by a data-acquisition system (TMR-211) at $10 \mathrm{~Hz}$ as shown in Figure 6(b). The relative slip $(\Delta \omega)$ between two concrete blocks was measured by a linear displacement sensor fixed on the surface of concrete block near the middle of the specimens as shown in Figure 7.

2.5. Test Program. In the experiment 20 specimens were divided into 6 groups, namely, A-1, B-1 3, and C-1 3, according to different temperature and humidity conditions. Group A-1 was used as reference specimens which were maintained at laboratory condition without pretreatment. Groups B and C were pretreated in the environmental chamber for 14 days with different temperature and humidity conditions. Group B tested the influence of temperature with the same humidity $95 \% \mathrm{RH}$. Three different test temperatures were used: $25^{\circ} \mathrm{C}, 50^{\circ} \mathrm{C}$, and $60^{\circ} \mathrm{C}$ corresponding to B-1, B-2, and B3 , respectively. Group $\mathrm{C}$ tested the influence of humidity with the same temperature $60^{\circ} \mathrm{C}$. Three different test humidity conditions were used: $60 \% \mathrm{RH}, 75 \% \mathrm{RH}$, and 95\% $\mathrm{RH}$ corresponding to C-1, C-2, and C-3, respectively. Conditions for $\mathrm{B}-3$ were the same as $\mathrm{C}-3$, so only one group of specimens 
TABLE 2: Details of the double shear tests.

\begin{tabular}{|c|c|c|c|}
\hline Group number & Hygrothermal conditions & Specimens number & Ultimate load $\left(P_{u} / \mathrm{kN}\right)$ \\
\hline \multirow{3}{*}{$A-1$} & \multirow{3}{*}{ Air environment untreated } & A-1-1 & 23.2 \\
\hline & & A-1-2 & 20.0 \\
\hline & & A-1-3 & 24.1 \\
\hline \multirow{3}{*}{ B-1 } & \multirow{3}{*}{$5^{\circ} \mathrm{C}, 95 \% \mathrm{RH}, 14$ days } & B-1-1 & 18.3 \\
\hline & & B-1-2 & 20.5 \\
\hline & & B-1-3 & 17.9 \\
\hline \multirow{4}{*}{ B-2 } & \multirow{4}{*}{$25^{\circ} \mathrm{C}, 95 \% \mathrm{RH}, 14$ days } & B-2-1 & 16.8 \\
\hline & & B-2-2 & 17.3 \\
\hline & & B-2-3 & 17.6 \\
\hline & & B-2-4 & 16.8 \\
\hline \multirow{4}{*}{ B-3 (C-3) } & \multirow{4}{*}{$60^{\circ} \mathrm{C}, 95 \% \mathrm{RH}, 14$ days } & B-3-1 & 17.2 \\
\hline & & B-3-2 & 16.0 \\
\hline & & B-3-3 & 15.3 \\
\hline & & B-3-4 & 16.4 \\
\hline \multirow{3}{*}{$\mathrm{C}-1$} & \multirow{3}{*}{$60^{\circ} \mathrm{C}, 60 \% \mathrm{RH}, 14$ days } & C-1-1 & 17.9 \\
\hline & & C-1-2 & 19.2 \\
\hline & & $\mathrm{C}-1-3$ & 20.0 \\
\hline \multirow{3}{*}{ C-2 } & \multirow{3}{*}{$60^{\circ} \mathrm{C}, 75 \% \mathrm{RH}, 14$ days } & $\mathrm{C}-2-1$ & 20.4 \\
\hline & & $\mathrm{C}-2-2$ & 17.5 \\
\hline & & $\mathrm{C}-2-3$ & 17.1 \\
\hline
\end{tabular}
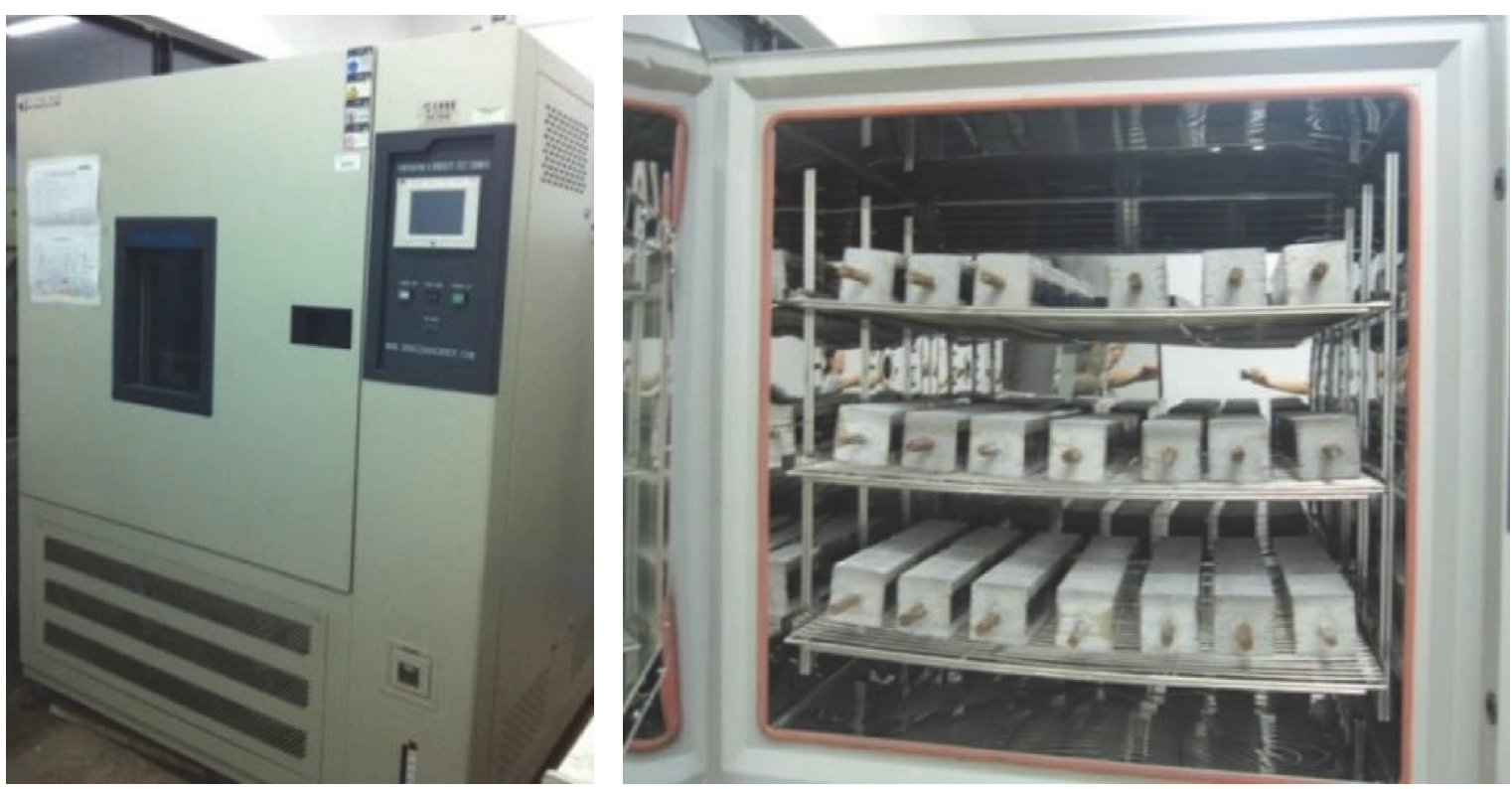

FIGURE 4: Programmable environmental chamber (HP-800U) and specimens. 
TABLE 3: Influence of hygrothermal environment on the ultimate load.

\begin{tabular}{lccc}
\hline Group & Conditions & Avg. $P_{u} / \mathrm{kN}$ & $\Delta P_{u} /\left(\right.$ reference $\left.P_{u}\right)$ \\
\hline A-1 & Lab. environment & 22.5 & Reference \\
B-1 & $5^{\circ} \mathrm{C}, 95 \% \mathrm{RH}$ & 18.9 & -16.0 \\
B-2 & $25^{\circ} \mathrm{C}, 95 \% \mathrm{RH}$ & 17.1 & -23.9 \\
B-3 & $60^{\circ} \mathrm{C}, 95 \% \mathrm{RH}$ & 16.2 & -27.9 \\
$\mathrm{C}-1$ & $60^{\circ} \mathrm{C}, 60 \% \mathrm{RH}$ & 19.1 & -15.2 \\
$\mathrm{C}-2$ & $60^{\circ} \mathrm{C}, 75 \% \mathrm{RH}$ & 18.3 & -18.4 \\
\hline
\end{tabular}

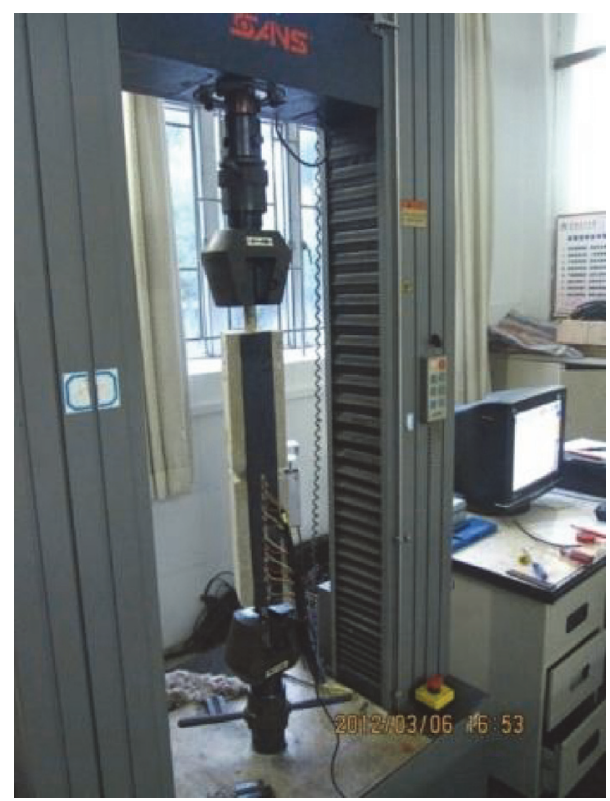

FIGURE 5: Electronic testing machine (type: CMT5105).

was tested for them. Details of the specimens are listed in Table 2.

\section{Results and Discussion}

3.1. Failure Mode. Only one typical debonding failure mode was observed in all specimens. As shown in Figure 8, a thin concrete layer attached to the surface of the debonded CFL shows that the debonding failure happened in the substrate concrete. Such failure mode is also widely reported in other resources $[17,18,20]$.

3.2. Hygrothermal Environment Effect on the Ultimate Load $\left(P_{u}\right)$. Table 3 summarizes the statistics of the ultimate loads for each group of specimens. Hygrothermal environment influence on the ultimate load was obtained by comparing the ultimate loads of the aged specimens with those of reference specimens as shown in Figure 9. In Figure 9(a), results for the reference specimens (A-1, without ageing) and those of group B subjected to different temperature with the same humidity are compared to analyze the temperature effect on the ultimate load. In Figure 9(b), results for the specimens under different humidity are compared.

A clear decrease of the ultimate load for the specimens exposed in hygrothermal environment can be observed except C-2-1. In general, higher temperature and humidity cause higher reduction in ultimate load.

The degree of influence of hygrothermal environment on the ultimate load is also presented in Table 3.

Comparing to the reference specimen group A-1, decreases of $16.0 \%, 23.9 \%$, and $27.9 \%$ are found for group $\mathrm{B}$ corresponding to $5^{\circ} \mathrm{C}, 25^{\circ} \mathrm{C}$, and $60^{\circ} \mathrm{C}$, respectively, with the same high humidity (95\%). For group C, the decreases are $15.2 \%, 18.4 \%$, and $27.9 \%$ corresponding to $60 \% \mathrm{RH}$, $75 \%$, and $90 \%$ relative humidity, respectively, with the same high temperature $\left(60^{\circ} \mathrm{C}\right)$. In particular, $P_{u}$ has a maximum decrease of $27.9 \%$ at $60^{\circ} \mathrm{C}$ and $95 \% \mathrm{RH}$.

3.3. Load-Deflection Curves. Figure 10 shows the total load versus deflection graphs for all the specimens tested. The curves of all the specimens in each group are similar to each other. Load-deflection data for C-1-2 were lost in the test.

The slope of the load-deflection curves reflects the total stiffness of the bond interface. It is steeper at the initial loading stage indicating good bond stiffness and then decreases with the increase of loading. The fluctuations in the curves indicate that local debonding happened on the bond face before the sudden failure.

The load-deflection curves of the reference specimens (without ageing) and group $\mathrm{B}$ specimens subjected to different temperatures $\left(5^{\circ} \mathrm{C}, 25^{\circ} \mathrm{C}\right.$, and $\left.60^{\circ} \mathrm{C}\right)$ with the same humidity (95\%) are compared in Figure 11(a) to analyze the temperature effect. The comparison between the reference specimens (without ageing) and group $\mathrm{C}$ specimens subject to different humidity $(60 \%, 75 \%$, and $95 \%)$ with the same temperature $\left(60^{\circ} \mathrm{C}\right)$ is shown in Figure $11(\mathrm{~b})$.

The results presented in Figure 11 clearly reveal that noticeable deterioration was caused by exposure in hygrothermal environment. Compared to the reference specimens, the smaller slopes of the curves for the aged specimens mean bond degradation and this becomes more obvious with increasing temperature and humidity.

\section{Influence of the Hygrothermal Environment on the Bond Behavior}

The results reported in this section indicate that the bond performance is significantly influenced by service temperature 


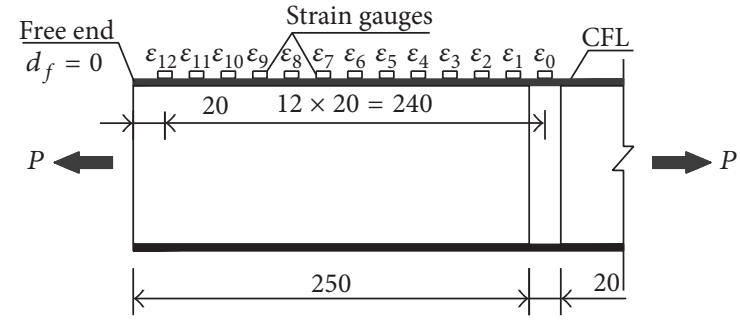

(a) Location of the strain gauges

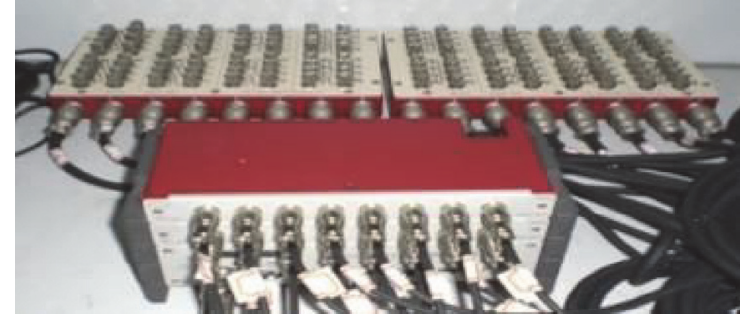

(b) Strain-recording instrument (type: TMR-211)

FIGURE 6: Measurement of strain.

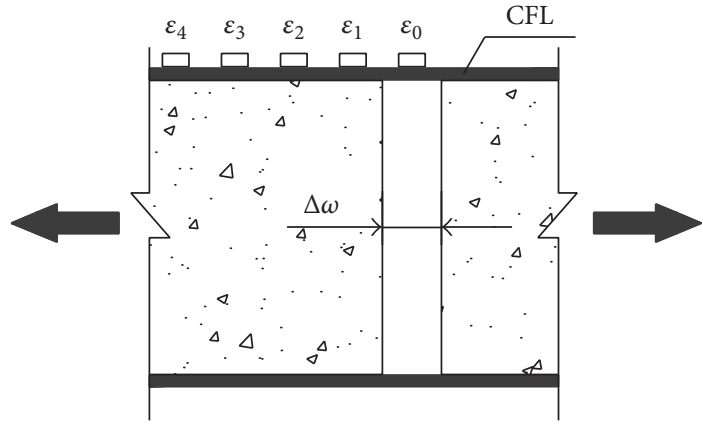

(a) Location of the linear displacement sensor

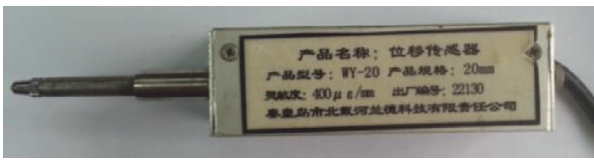

(b) Linear displacement sensor (type: WY-20)

FIGURE 7: Measurement of relative slip between the concrete blocks.

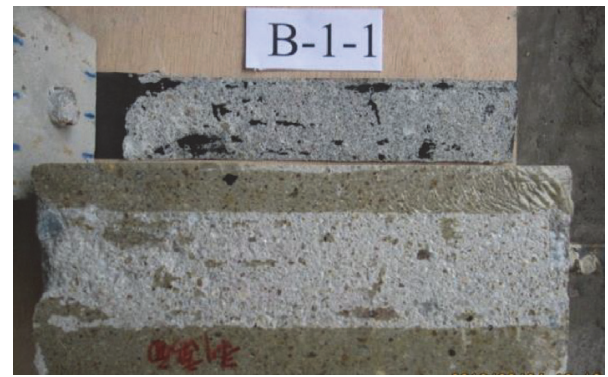

FIgURE 8: Typical bond failure mode.

and humidity. As a result, hygrothermal environment effects must be properly taken into account from the design point of view.

4.1. Relative Slips between the Two Concrete Blocks. The relative slips $(\Delta \omega)$ at different load levels between the two concrete blocks were obtained by the linear displacement sensor fixed on the concrete blocks which reflected the total bond stiffness indirectly. In this test, the slip measurements for some specimens such as A-1-1 and A-1-3 and C-1 and C-2 failed because of the difficulty of fixing the displacement sensor effectively. Figure 12 shows some relative displacementload curves for specimens with different temperatures. The typical experimental relative slip-load response has a 3-stage characteristic containing an initial linear growth stage, a rapid growth stage, and an instable growth stage. Compared to the reference specimens in group $\mathrm{A}$, the slopes of the relative slip-load curves of group B specimens were higher which indicated faster degradation of the bond behavior. As for group B aged with different temperatures under the same high humidity ( $95 \% \mathrm{RH})$, the higher the ageing temperature was, the faster the speed rate grew. However, the ultimate relative slips of all specimens were not sensitive to temperature and humidity and all were in the range of $0.7 \mathrm{~mm}$ and $0.8 \mathrm{~mm}$.

4.2. Strain Distribution in the CFL. These strains were read from the strain gauges mounted on the upper surface of the CFL as shown in Figure 6. Longitudinal strains in the CFL at various load levels for each specimen are shown in Figure 13, where the horizontal axis $d_{f}$ is the distance from the free end of the CFL shown in Figure 6, and the vertical axis is the measured strains of the CFL.

In general, the external loads were transferred through the concrete blocks into the CFL over a range of $100 \mathrm{~mm}$ to 


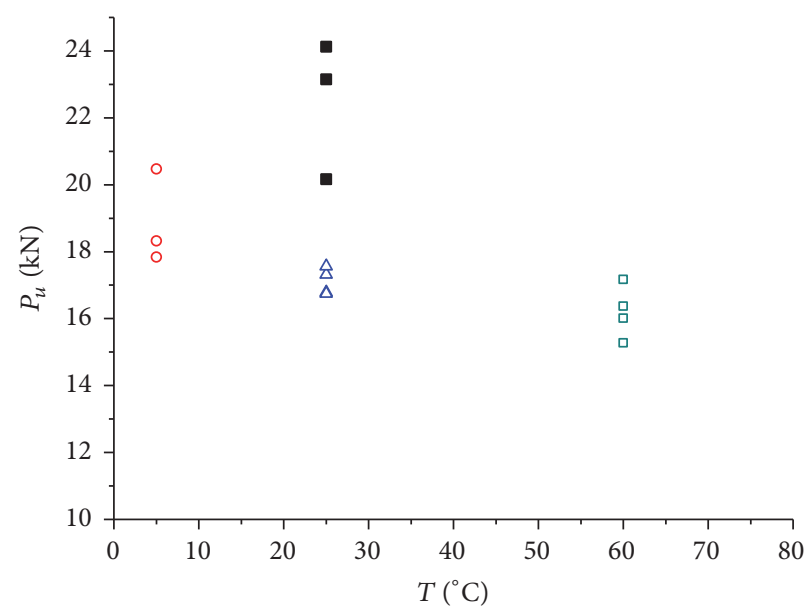

- A-1 reference specimens

- B- $15^{\circ} \mathrm{C}, 95 \% \mathrm{RH}$

(a) Influence of temperature

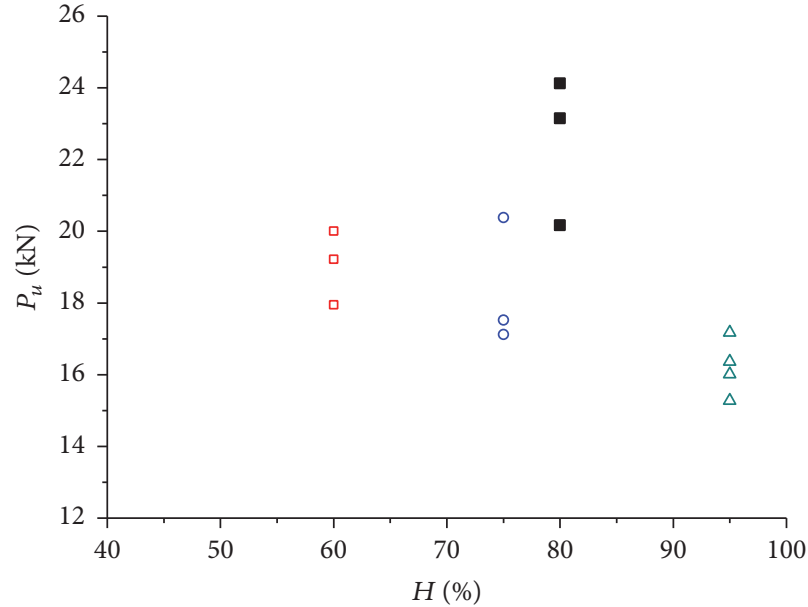

- A-1 reference specimens $\quad \mathrm{C}-260^{\circ} \mathrm{C}, 75 \%$

ㅁ $\mathrm{C}-160^{\circ} \mathrm{C}, 60 \% \quad \triangle \mathrm{B}-360^{\circ} \mathrm{C}, 95 \%$

(b) Influence of humidity

FIGURE 9: Influence of the hygrothermal environment on the ultimate load.

Group A-1 reference specimens

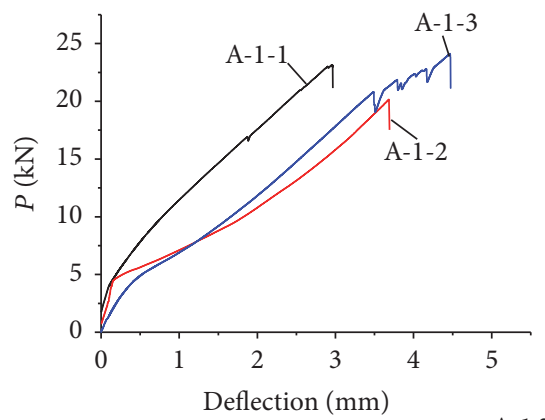

A-1-3

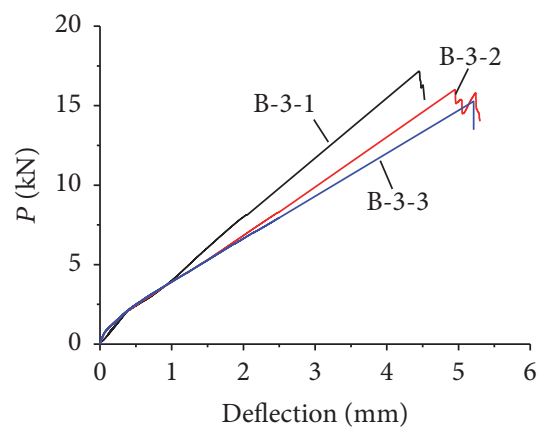

— Group B-3 $60^{\circ} \mathrm{C}, 95 \%$

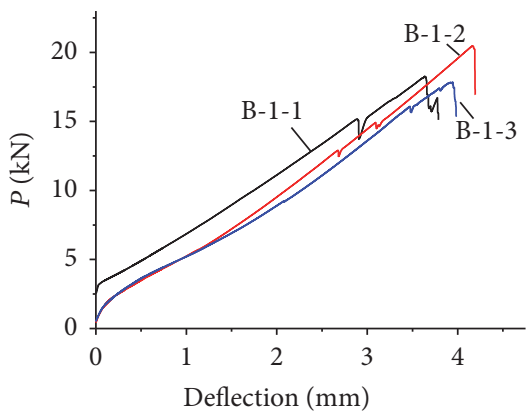

- Group B-1 $5^{\circ} \mathrm{C}, 95 \%$

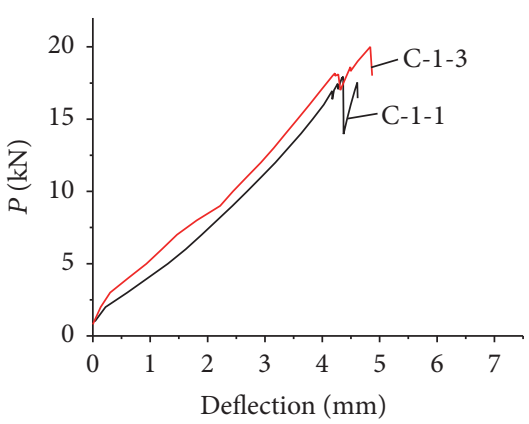

- Group C- $160^{\circ} \mathrm{C}, 60 \%$

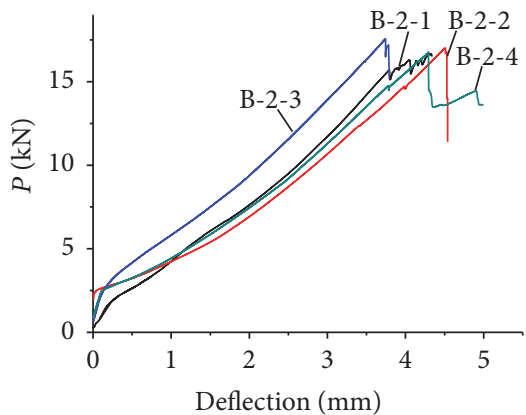

Deflection (mm)

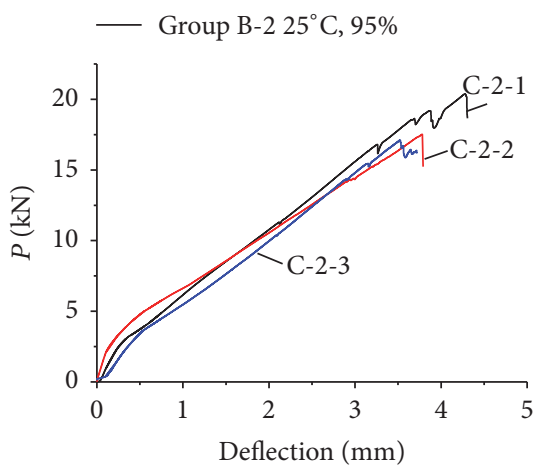

- Group C-2 $60^{\circ} \mathrm{C}, 75 \%$

FIGURE 10: Load-deflection curves of all the specimens. 


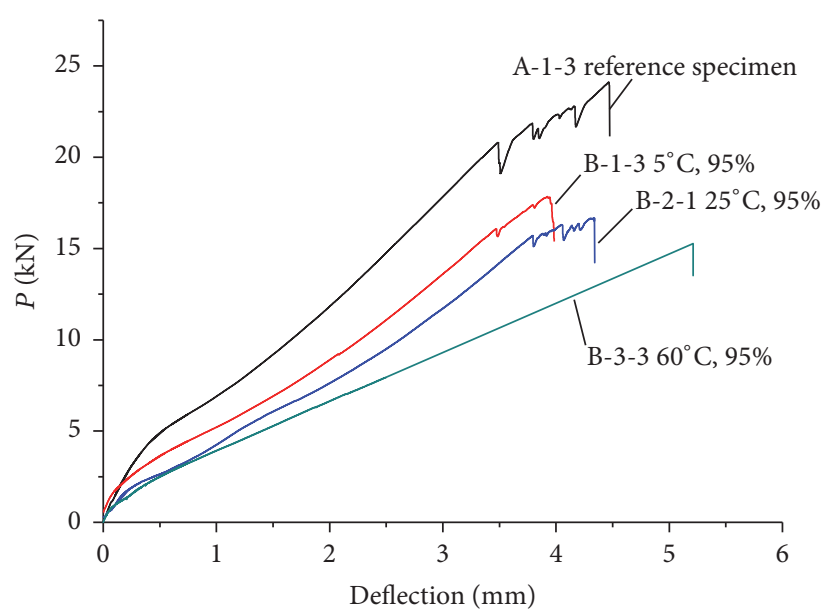

(a) Effect of temperature

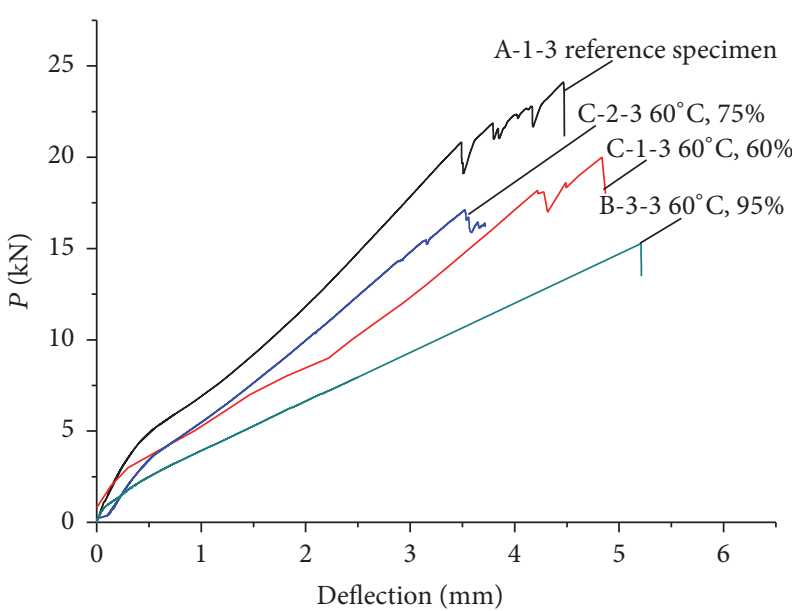

(b) Effect of humidity

FIGURE 11: Effect of hot-wet environment on the load-deflection curves.

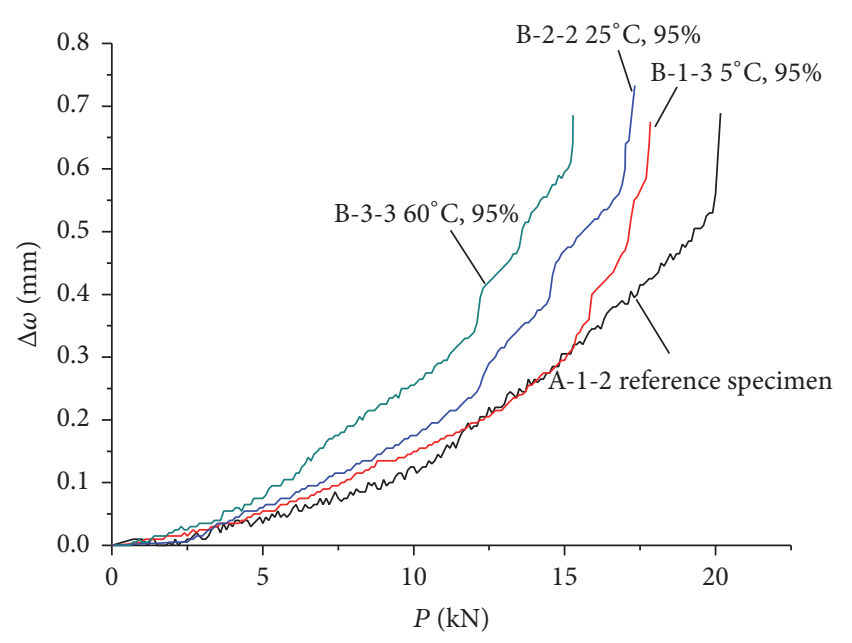

FIgURE 12: Hot-wet pretreatments effect on the relative slips $(\Delta \omega)$.

$150 \mathrm{~mm}$ at each side of the gap. The strain of the CFL was at maximum at the gap location and reduced at the locations away from the gap. The strains also increased with external loading. It needs to be noted that the strain distribution across the width of the CFL was not uniform due to the imperfection in loading and/or geometry.

Compared with the reference specimens (group A-1), the maximum strains $\left(\varepsilon_{\max }\right)$ of the specimens in groups $\mathrm{B}$ and $\mathrm{C}$ decreased obviously which indicated decay of the bond behavior after exposure to the hygrothermal environment. The maximum strains were 5500 6000 $\mu \varepsilon, 3500 \sim 4500 \mu \varepsilon$, and 3500 5000 $\mu \varepsilon$ for groups A-1, B-2 3, and C-2, respectively. This means that the aggressive environment caused premature debonding failure along the interface.

\section{Conclusions}

This study experimentally investigated the bond-slip behavior of the CFL-concrete bond subjected to static load after hygrothermal environment exposure. The failure modes, load-deflection, relative slip, and strain distributions in CFL were measured and analyzed in detail.

The following conclusions can be drawn based on the experimental data:

(1) Hygrothermal environment adversely affected the bond behavior of the CFL-concrete interface. Compared to the reference specimen, the ultimate load decreased as much as $27.9 \%$ when the specimens exposed to the hygrothermal environment of $60^{\circ} \mathrm{C}$ and $95 \% \mathrm{RH}$.

(2) Hygrothermal environment exposure caused noticeable deterioration of the bond stiffness shown in the load-deflection curves and relative slips curves. As temperature and humidity increased, the slopes of the curves for the aged specimens decreased.

(3) Compared with the reference specimens, the maximum strains $\left(\varepsilon_{\max }\right)$ of the specimens subjected to hygrothermal environment pretreatment decreased from $5500 \sim 6000 \mu \varepsilon$ to $3500 \sim 5000 \mu \varepsilon$. Furthermore, the effective bond length increased from about $100 \mathrm{~mm}$ to near $150 \mathrm{~mm}$, which indicated bond behavior degradation.

\section{Competing Interests}

The authors declare that there is no conflict of interests regarding the publication of this paper. 

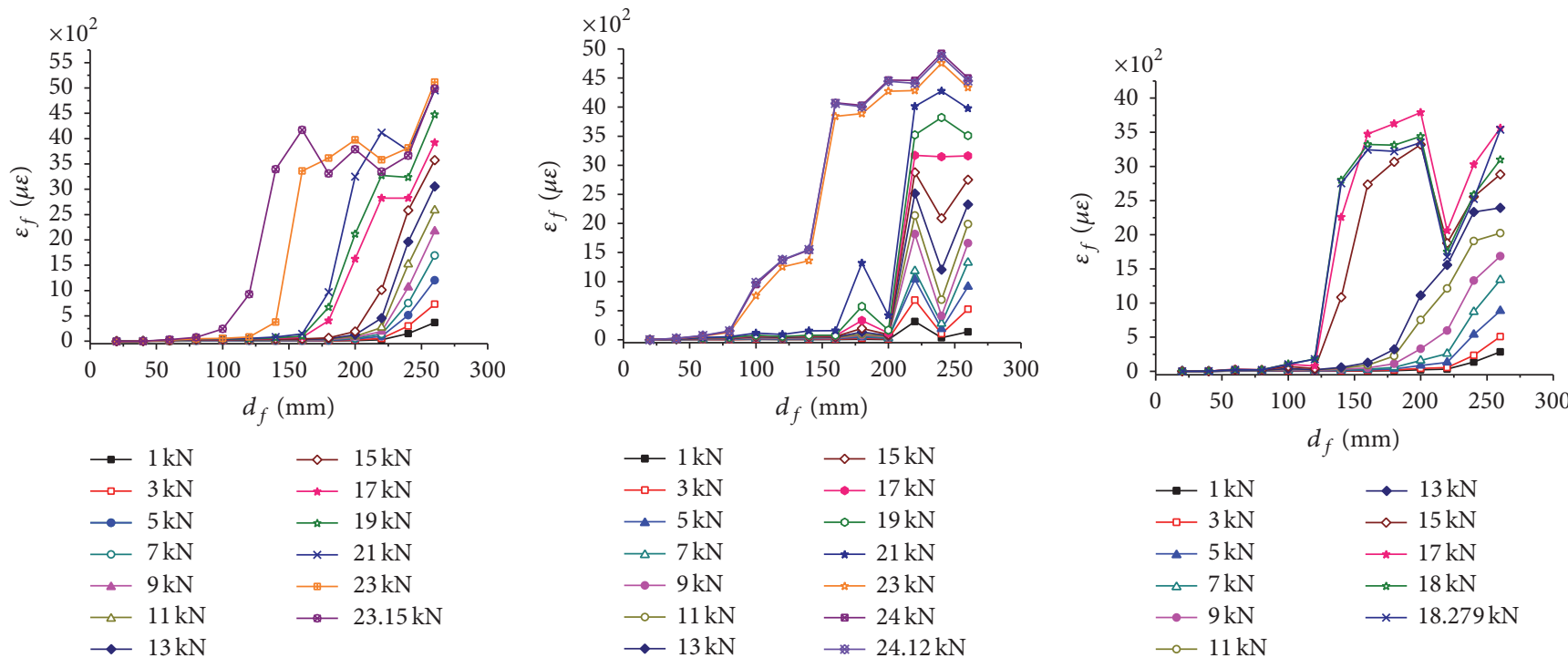

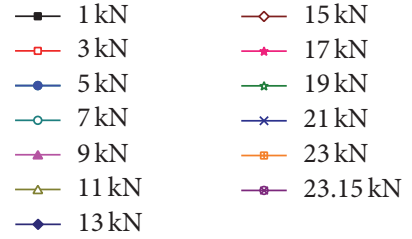

(a) A-1-1 reference specimen
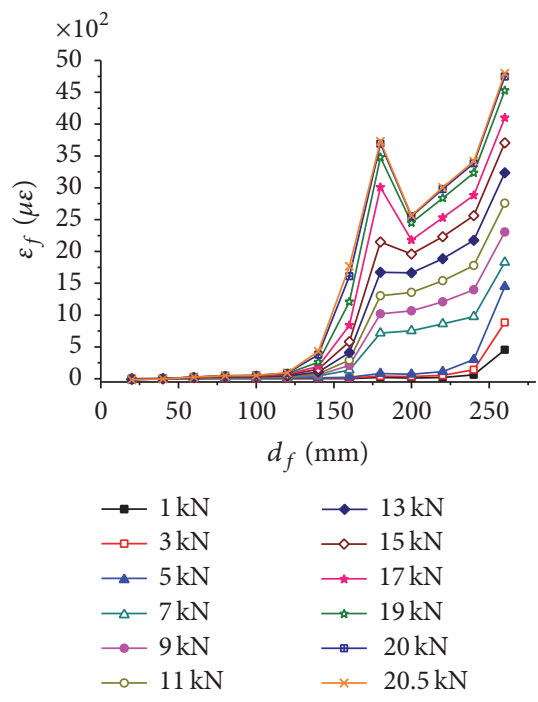

(d) $\mathrm{B}-1-25^{\circ} \mathrm{C}, 95 \%$

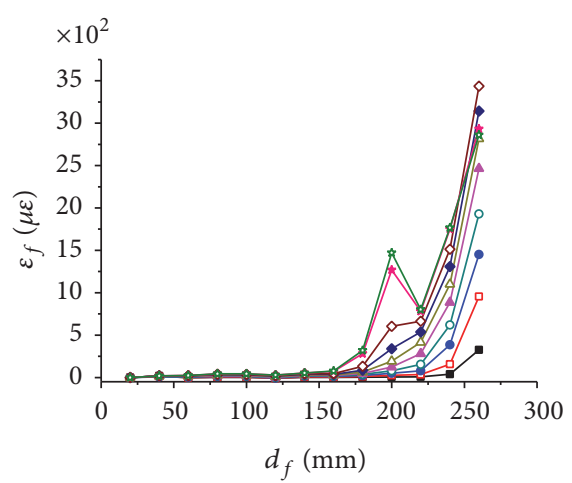

$$
\begin{aligned}
& \rightarrow 1 \mathrm{kN} \\
& \multimap-3 \mathrm{kN} \\
& \multimap 5 \mathrm{kN} \\
& \multimap-7 \mathrm{kN} \\
& \rightarrow 9 \mathrm{kN} \\
& -11 \mathrm{kN} \\
& \rightarrow 13 \mathrm{kN}
\end{aligned}
$$

(g) $\mathrm{B}-3-160^{\circ} \mathrm{C}, 95 \%$

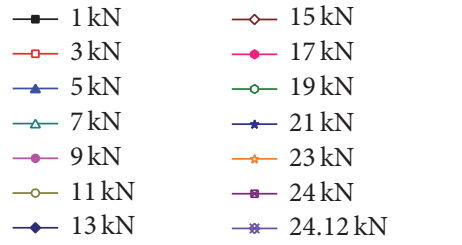

(b) A-1-3 reference specimen
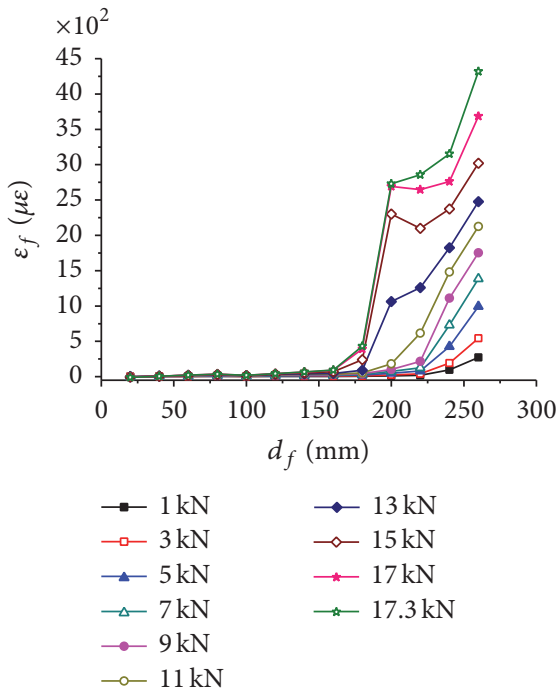

(e) B- $2-225^{\circ} \mathrm{C}, 95 \%$

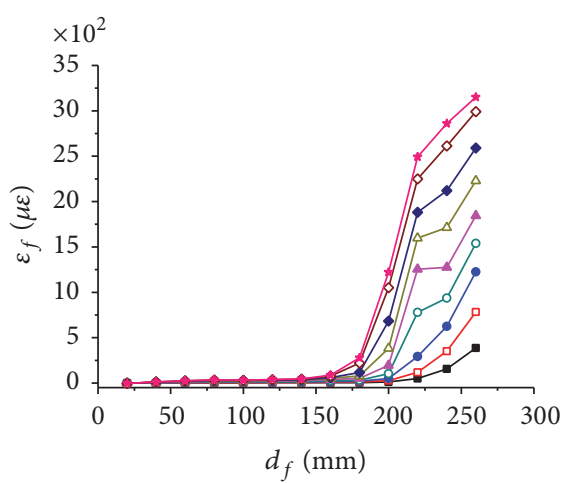
$\rightarrow 1 \mathrm{kN}$
$\longrightarrow-3 \mathrm{kN}$
$\longrightarrow 5 \mathrm{kN}$
$\multimap-7 \mathrm{kN}$
$\because 9 \mathrm{kN}$
$\triangle 11 \mathrm{kN}$
$\longrightarrow 13 \mathrm{kN}$

(h) B-3-2 $60^{\circ} \mathrm{C}, 95 \%$ (c) $\mathrm{B}-1-15^{\circ} \mathrm{C}, 95 \%$

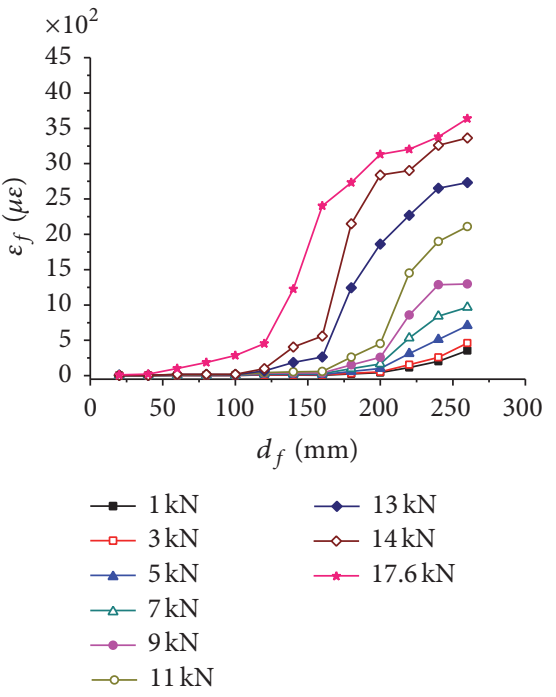

(f) $\mathrm{B}-2-325^{\circ} \mathrm{C}, 95 \%$

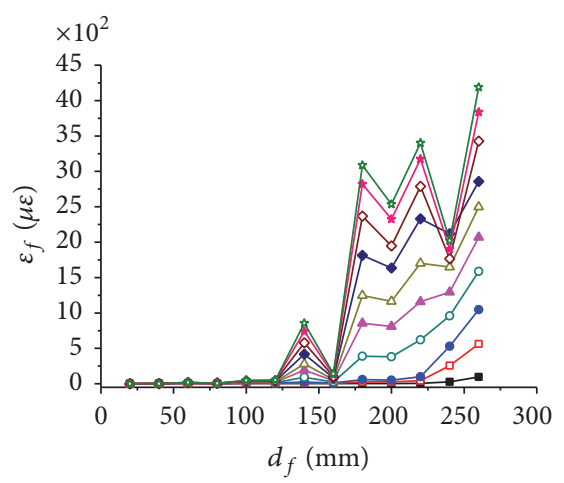

Figure 13: Continued. 


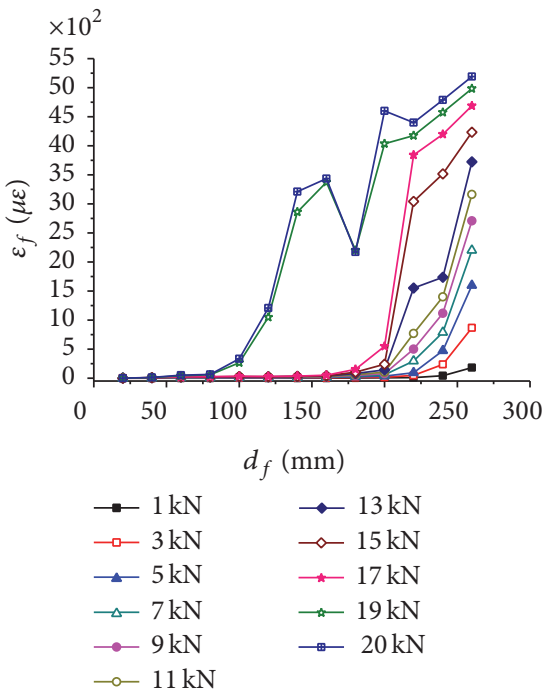

(j) $\mathrm{C}-1-360^{\circ} \mathrm{C}, 60 \%$

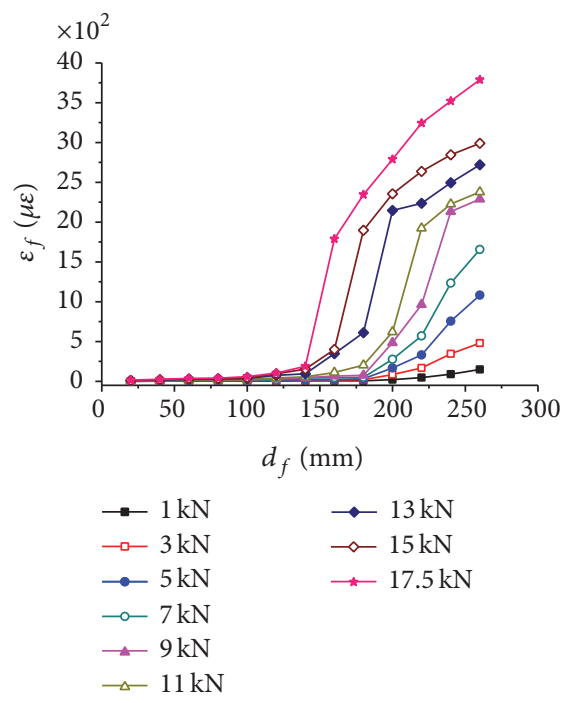

(k) $\mathrm{C}-2-260^{\circ} \mathrm{C}, 75 \%$

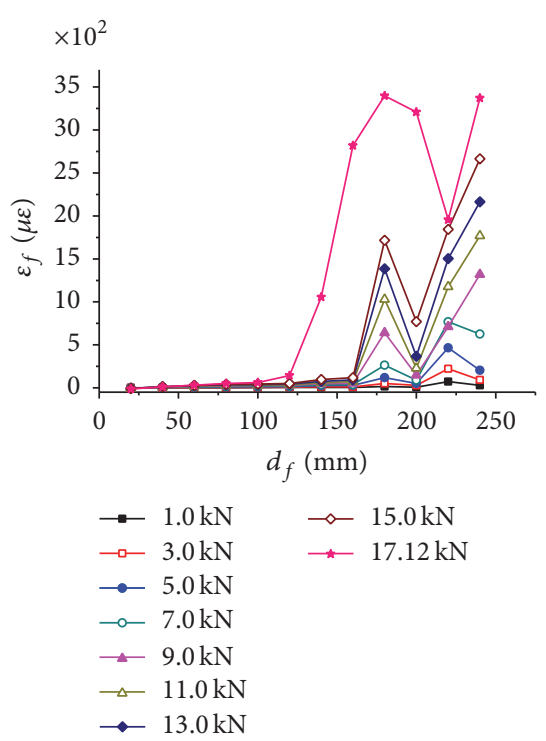

(l) $\mathrm{C}-2-360^{\circ} \mathrm{C}, 75 \%$

FIgURE 13: Strain distributions for groups A to C specimens.

\section{Acknowledgments}

The project was supported by the National Natural Science Foundation of China (nos. 11132004, 11627802, 51678249, and 51508202), China Scholarship Council (no. 201606155018), Guangdong Province Natural Science Foundation of China (no. 2016A030310414), and Open Project for Key Laboratory Construction of Mountainous Bridges and Tunnels in Chongqing Jiaotong University (no. CQSLBF-Y16-9).

\section{References}

[1] V. M. Karbhari, F. Seible, R. Burgueño, A. Davol, M. Wernli, and L. Zhao, "Structural characterization of fiber-reinforced composite short- and medium-span bridge systems," Applied Composite Materials, vol. 7, no. 2, pp. 151-182, 2000.

[2] J. G. Teng, J. F. Chen, S. T. Smith, and L. Lam, FRP-Strengthened RC Structures, John Wiley and Sons, Chichester, UK, 2002.

[3] D. J. Oehlers and R. Seracino, Design of FRP and Steel Plated RC Structures: Retrofitting Beams and Slabs for Strength, Stiffness and Ductility, Elsevier, London, UK, 2004.

[4] J. G. Teng and J. F. Chen, "Mechanics of debonding in FRPplated RC beams," Proceedings of the Institution of Civil Engineers: Structures and Buildings, vol. 162, no. 5, pp. 335-345, 2009.

[5] Y.-F. Wu and C. Jiang, "Quantification of bond-slip relationship for externally bonded FRP-to-concrete joints," Journal of Composites for Construction, vol. 17, no. 5, pp. 673-686, 2013.

[6] Y.-F. Wu, X.-S. Xu, J.-B. Sun, and C. Jiang, "Analytical solution for the bond strength of externally bonded reinforcement," Composite Structures, vol. 94, no. 11, pp. 3232-3239, 2012.

[7] P. Mukhopadhyaya, R. N. Swamy, and C. J. Lynsdale, "Influence of aggressive exposure conditions on the behaviour of adhesive bonded concrete-GFRP joints," Construction and Building Materials, vol. 12, no. 8, pp. 427-446, 1998.

[8] R. Sen, "Developments in the durability of FRP-concrete bond," Construction and Building Materials, vol. 78, pp. 112-125, 2015.
[9] H. C. Biscaia, M. A. G. Silva, and C. Chastre, "An experimental study of GFRP-to-concrete interfaces submitted to humidity cycles," Composite Structures, vol. 110, pp. 354-368, 2014.

[10] J. F. Davalos, S. S. Kodkani, I. Ray, and Chunfu Lin, "Fracture evaluation of GFRP-concrete interfaces for freeze-thaw and wet-dry cycling," Journal of Composite Materials, vol. 42, no. 14, pp. 1439-1466, 2008.

[11] J. Lyons, D. Laub, V. Giurgiutiu, M. Petrou, and H. Salem, "Effect of hygrothermal aging on the fracture of composite overlays on concrete," Journal of Reinforced Plastics and Composites, vol. 21, no. 4, 2002.

[12] B. L. Wan, M. F. Petrou, and K. A. Harries, "The effect of the presence of water on the durability of bond between CFRP and concrete," Journal of Reinforced Plastics and Composites, vol. 25, no. 8, pp. 875-890, 2006.

[13] K. Benzarti, S. Chataigner, M. Quiertant, C. Marty, and C. Aubagnac, "Accelerated ageing behaviour of the adhesive bond between concrete specimens and CFRP overlays," Construction and Building Materials, vol. 25, no. 2, pp. 523-538, 2011.

[14] J. C. P. H. Gamage, R. Al-Mahaidi, and M. B. Wong, "Bond characteristics of CFRP plated concrete members under elevated temperatures," Composite Structures, vol. 75, no. 1-4, pp. 199205, 2006.

[15] M. A. G. Silva and H. Biscaia, "Degradation of bond between FRP and RC beams," Composite Structures, vol. 85, no. 2, pp. 164-174, 2008.

[16] W. L. Lai, S. C. Kou, C. S. Poon, W. F. Tsang, and K. K. Lee, "A durability study of externally bonded FRP-concrete beams via full-field infrared thermography (IRT) and quasi-static shear test," Construction and Building Materials, vol. 40, pp. 481-491, 2013.

[17] B. P. Blackburn, J. Tatar, E. P. Douglas, and H. R. Hamilton, "Effects of hygrothermal conditioning on epoxy adhesives used in FRP composites," Construction and Building Materials, vol. 96, pp. 679-689, 2015.

[18] J. Shrestha, T. Ueda, and D. Zhang, "Durability of FRP concrete bonds and its constituent properties under the influence of 
moisture conditions," Journal of Materials in Civil Engineering, vol. 27, no. 2, Article ID A4014009, 2015.

[19] C. Mikami, H.-C. Wu, and A. Elarbi, "Effect of hot temperature on pull-off strength of FRP bonded concrete," Construction and Building Materials, vol. 91, pp. 180-186, 2015.

[20] M. I. Kabir, R. Shrestha, and B. Samali, "Effects of applied environmental conditions on the pull-out strengths of CFRPconcrete bond," Construction and Building Materials, vol. 114, pp. 817-830, 2016.

[21] "Standard for test method of mechanical properties on ordinary concrete," GB/T 50081-2002, Ministry of Construction P. R. China, 2002.

[22] P. Y. Huang and J. C. Zeng, "Carbon fiber laminate and application,” ZL200410026742.8, 2006.

[23] "Standard for test method of mechanical properties on ordinary concrete," Tech. Rep. GB/T 50081-2002, Ministry of Construction P. R. China, 2002.

[24] P. Y. Huang, H. Zhou, X. H. Zheng, and X. Y. Guo, "On the experimental method for durability measurement of RC members strengthened with FRP served in hot and humid environments," Journal of Experimental Mechanic, vol. 26, no. 5, pp. 603-610, 2011.

[25] GB/T1446-2005, "Fiber-reinforced plastics composites-the generals for determination of properties," Ministry of Communications of the People's Republic of China, 2005.

[26] GB/T2573-2008, Test Method for Aging Properties of Glass Fiber Reinforced Plastics, Ministry of Communications of the People's Republic of China, 2008. 

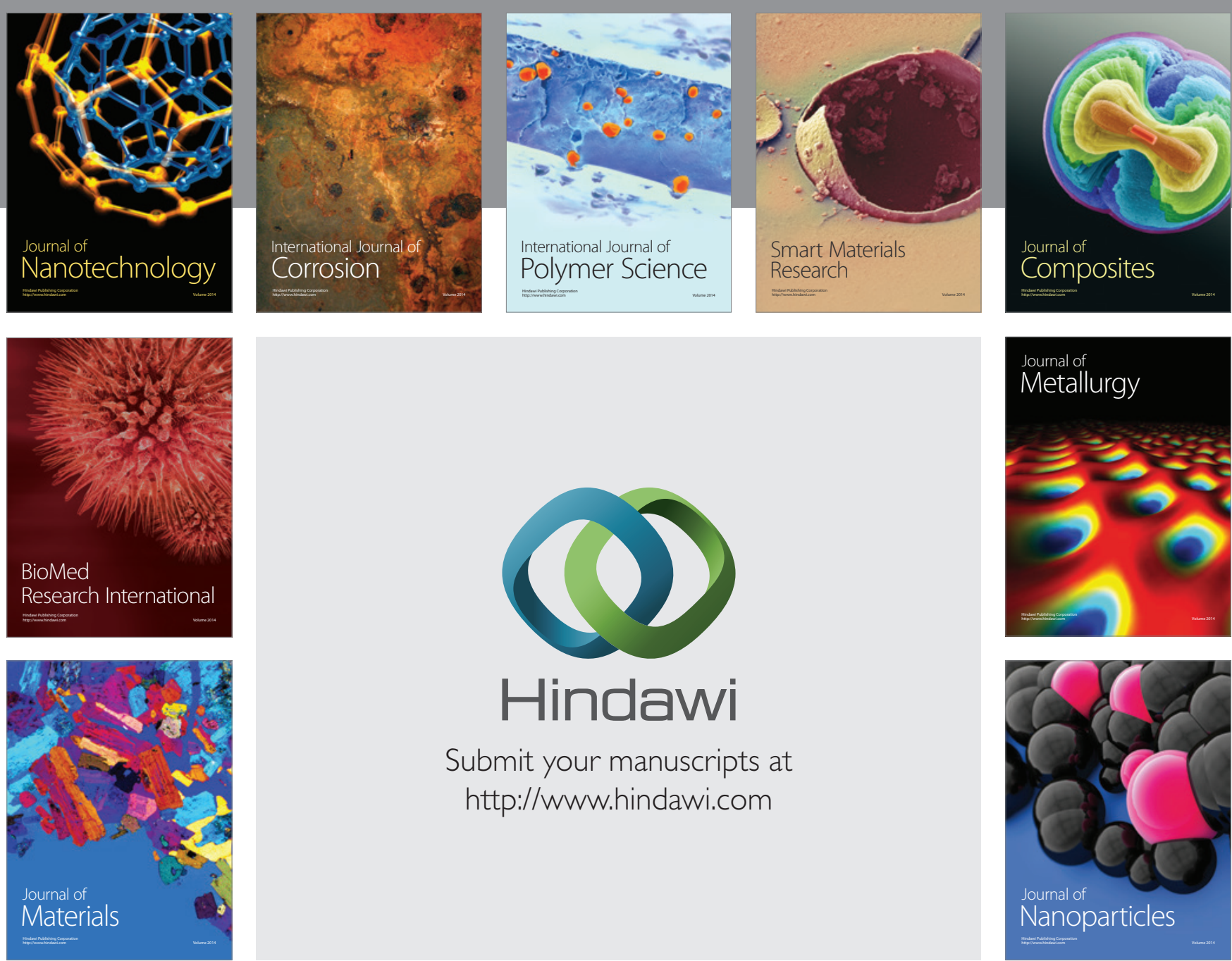

\section{Hindawi}

Submit your manuscripts at

http://www.hindawi.com

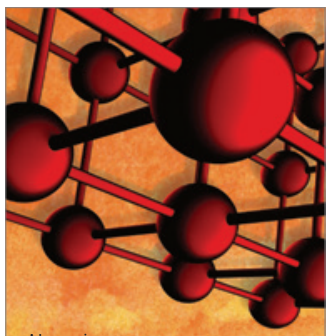

Materials Science and Engineering
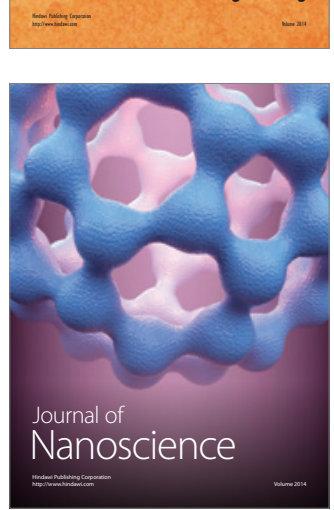
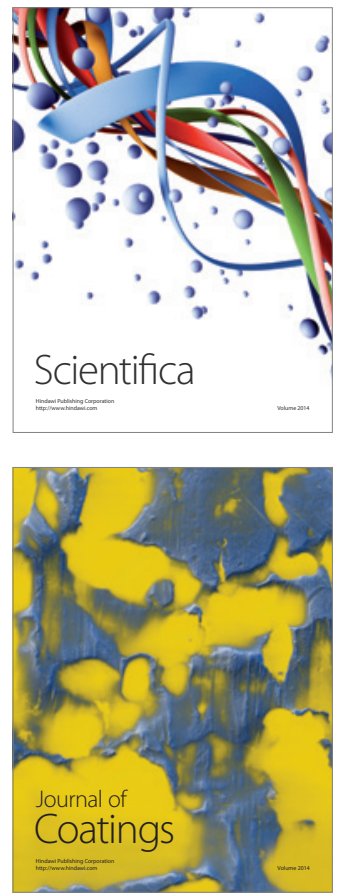
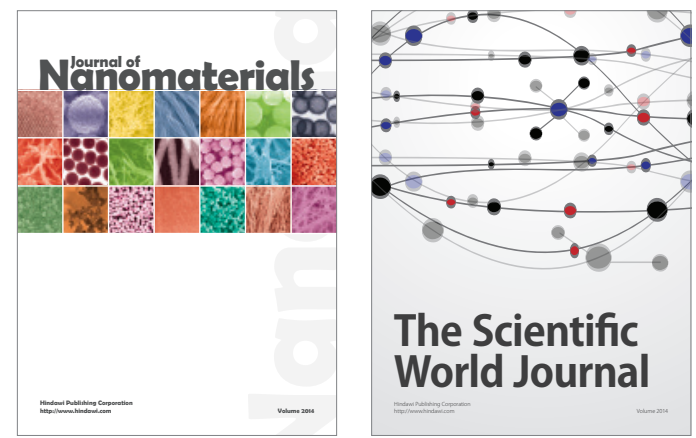

The Scientific World Journal
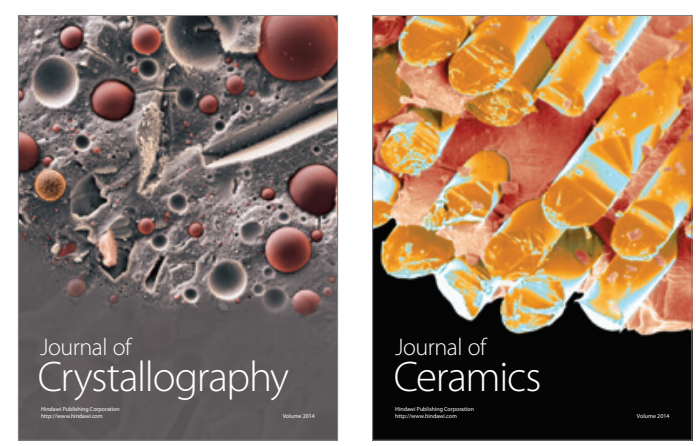
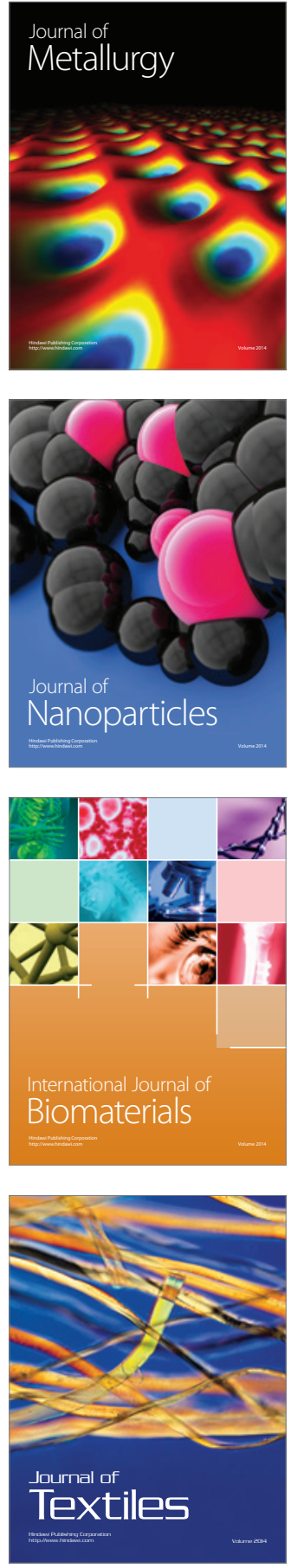